\title{
El deber de fidelidad entre los cónyuges: daños por incumplimiento en el tratamiento de los tribunales españoles*
}

The duty of fidelity between spouses: damages caused by non-compliance and the treatment given by Spanish courts

\section{Cristina de Amunátegui Rodríguez ${ }^{* *}$}

\section{RESUMEN}

En este trabajo se analiza el significado actual del deber de fidelidad en el contexto del Código Civil Español, a la vista de cómo es tratado por los tribunales.

El establecimiento de un divorcio acausal ha significado un cambio en la valoración de los deberes que incumben a los casados, no asociándose la separación o divorcio con el incumplimiento de los deberes entre ellos, especialmente el de fidelidad.

El argumento preferido del Tribunal Supremo consiste en negar las pretensiones de daños por infidelidad al existir una consecuencia legal especifica para ello, como la separación. Sin embargo, este ha perdido su valor, dejando a los jueces inmersos en una posición de incertidumbre. Asi, se ha ido abriendo camino una línea de resolución particular que permite el reclamo de indemnizaciones por el hecho de que se oculte al otro cónyuge la verdadera filiación de los hijos, concebidos como resultado de la otra relación constante de matrimonio.

PALABRAS CLAVE: Matrimonio, deberes conyugales, infidelidad, reclamación de daños, práctica de los tribunales.

\begin{abstract}
This study analyses the contemporary meaning of the duty of fidelity in the context of the Spanish Civil Code, in terms of its treatment in court.

The establishment of the no-fault divorce has led to a change in the value given to spousal duties, with separation or divorce not associated with the failure to fulfil said duties, especially those pertaining to fidelity.

The argument preferred by the Supreme Court is based on the denial of claims for damages caused by infidelity. With the existence of a specific legal consequence for infidelity, such as separation, this argument has lost value. This has placed judges in a position of uncertainty, which led to the establishment of a private solution that allows the claim for compensation when one spouse has hidden from the other the true parentage of the children conceived as a result of the other constant/long-term relationship.
\end{abstract}

KEY WORDS: Matrimony/marriage, spousal duties, infidelity, damages claims, court practice

\footnotetext{
* Artículo de investigación. Recibido el 16 de septiembre de 2018 y aceptado para su publicación el 29 de abril de 2019.

** Catedrática de Derecho Civil en la Universidad Complutense de Madrid, España. (crisamu@ucm.es) orcid.org/ 0000-0003-0841-7436
} 


\section{SUMARIO}

1. Planteamiento inicial

2. Las reclamaciones de daños entre los cónyuges

3. El deber de fidelidad y su incumplimiento

4. Tratamiento por parte de los tribunales respecto a las reclamaciones de daños por incumplimiento de la fidelidad

5. Breves conclusiones

\section{Planteamiento inicial}

Antes de comenzar a analizar el tratamiento que dispensan los tribunales españoles a las reclamaciones por incumplimiento del deber de fidelidad, quiero destacar los cambios que ha experimentado nuestro ordenamiento en los últimos tiempos pues, de algún modo, incide sustancialmente en el análisis de esta cuestión.

El Código Civil no define el matrimonio más que en el artículo 44, el cual fue modificado en el año 2015 para permitir el matrimonio entre personas del mismo sexo. Este determina que: "El hombre y la mujer tienen derecho a contraer matrimonio conforme a las disposiciones de este Código. El matrimonio tendrá los mismos requisitos y efectos cuando ambos contratantes sean del mismo o de diferente sexo". Más adelante, al mencionar el conjunto de deberes, incluye en la primera parte del artículo 68 que los esposos "están obligados a vivir juntos, guardarse fidelidad y socorrerse mutuamente”.

Durante décadas, una de las consecuencias directas del incumplimiento del deber de fidelidad residía en que se consideraba causa de separación conyugal. Tal situación cambia con la reforma obrada en el año 2005, por la cual se suprimen las causas de separación. Así, se establece un divorcio acausal, considerando además que el derecho de quien quiere salir del matrimonio forma parte del libre desarrollo de la personalidad, de modo que no pueden existir trabas a su ejercicio. En contrapartida, no se modifica la relación de deberes conyugales, que queda, en mi opinión, como una descripción de lo que debería ser el matrimonio ideal. Esto en el sentido de que contiene una declaración programática de que los esposos deben respetarse, ayudarse, actuar en interés de la familia, socorrerse, ser fieles e incluso compartir las tareas domésticas y de cuidado de familiares a su cargo, pero poco más. 
Independizados de las causas de ruptura, se observa que algunos de esos incumplimientos tienen respuesta en el ordenamiento (todos los dirigidos al sostenimiento económico de la familia), pero otros no; concretamente, el de fidelidad. Ello abre el debate de si es posible plantear reclamaciones de daños por el mero incumplimiento de ese deber en concreto, al no existir ya ninguna consecuencia inmediata para su infracción, siendo, como es, incoercible.

\section{Las reclamaciones de daños entre los cónyuges}

No puede afirmarse que la observación de posibles pretensiones indemnizatorias entre esposos constituya una materia nueva, aunque sí ha experimentado una considerable evolución en los últimos tiempos en los países de nuestro entorno. Tradicionalmente, se han estimado como límites tanto el que las reclamaciones de daños chocaran con el principio de inmunidad de la familia, así como la presencia de una correlativa autosuficiencia de las reglas de derecho de familia para solucionar las controversias entre sus miembros.

Además, existen otras razones, como la preservación de la paz familiar, ${ }^{1}$ la solidaridad, la presencia de reglas no escritas de usos sociales, o el peligro de proliferación de este tipo de pretensiones. Tales razones se fueron atenuando con el tiempo, especialmente por las consecuencias de los frecuentes accidentes de tráfico, junto a la implantación de seguros, y la evolución de las reglas del derecho de familia. Creo que el crecimiento de este tipo de demandas se debe en gran parte -al menos en nuestro país- a la regulación de las acciones de reclamación e impugnación de paternidad (por obra de la reforma del Código de 1981). Asimismo, a la generalización de pruebas de paternidad de gran fiabilidad y a cuyo recurso pueden acceder los particulares de forma sencilla y económica. ${ }^{2}$

Desde luego no puede obviarse que en el marco del derecho de familia existen reglas propias, algunas de carácter indemnizatorio o compensador, que resultan de ciertos incumplimientos de deberes. ${ }^{3}$ Tampoco se debe dejar de lado

\footnotetext{
1 Destacada recientemente, por ejemplo, en la Sentencia de la Audiencia Provincial de Alicante (S. 9. a) de 6 de noviembre de 2017, en la que entablada la demanda contra el verdadero padre del hijo se desestima, no considerándolo culpable por no interponer una demanda de impugnación por el hecho de tener simples sospechas al ser "ajeno al círculo familiar y un extraño", no debiendo irrumpir en una familia con sus afectos consolidados.

2 Destacan estas circunstancias Garcia Amado, Juan Antonio, "La familia y su derecho", Diálogos Jurídicos, Universidad de Oviedo, Aranzadi, 2016, pp. 24 y ss. y Farnós Amorós, Esther, "Daño moral en las relaciones familiares", en Gómez Pomar, Fernando y Marín García, Ignacio (dirs.), El daño moral y su cuantificación, Barcelona, Bosch, 2015, p. 541.

${ }^{3}$ Entre otros, incumplimiento de promesa de matrimonio (artículos 42 y 43 Código Civil (cc); efectos indemnizatorios de la declaración de nulidad matrimonial para el cónyuge de buena fe (artículos 95 y 98 cc); compensación económica en rupturas matrimoniales (artículo 97 cc); causa de desheredación para el cónyuge que incumpla sus deberes (artículo 855); y más en el marco del régimen económico matrimonial.
} 
que, en el campo del derecho penal, numerosos tipos delictivos protegen ciertos derechos familiares. ${ }^{4}$ Ambas circunstancias no permiten hablar de inmunidad absoluta en el seno de las relaciones familiares.

También avanza camino el reconocimiento de posible vulneración o infracción de derechos fundamentales entre los esposos, solapándose a veces la protección penal y la civil, por ejemplo, la libertad (coacciones), la libertad ambulatoria (detención ilegal), la libertad sexual, la intimidad, el honor, el libre desarrollo de la personalidad, entre otros, derechos esgrimibles, todos ellos, entre extraños o entre integrantes de matrimonios o parejas.

En mi opinión, esta última apreciación, como quiebra del principio de inmunidad, abre una interesante vía por explorar, a la vista de algunos procedimientos judiciales en los que resulta evidente la conculcación del honor o la intimidad del otro. Como señalaré más adelante, si de las circunstancias que rodean cada supuesto en concreto puede deducirse una agresión a derechos como el honor (escarnio social, comportamientos especialmente insultantes que impliquen un trato degradante, humillante, etcétera) o intimidad, podría reclamarse la correspondiente indemnización. ${ }^{5}$

\section{El deber de fidelidad y su incumplimiento}

Desde la primera edición del Código Civil, la fidelidad se ha considerado como uno de los deberes integrantes del matrimonio, si bien su tratamiento y consecuencias se han ido transformando a lo largo de los años. Sin duda, la valoración social de la misma ha cambiado sustancialmente, pasando de considerarse algo censurable, e incluso delictivo -especialmente en el caso de las mujeres, pues el adulterio de la esposa se consideró delito durante un tiempo-, a formar parte del contenido que integra la libertad y autodeterminación sexual de la persona. En tal sentido, esta libertad no puede coartarse,

\footnotetext{
${ }^{4}$ La responsabilidad penal de suyo determina responsabilidad civil conforme a lo que disponen los artículos 109 y 110 del Código Penal español (cP). Además existen numerosos tipos delictivos, algunos de nuevo cuño que protegen la familia y derechos de sus miembros, como, entre otros muchos, delitos por impago de pensiones (artículo 227 cP); abandono de familia (artículo 226.1 cP); delitos contra la libertad e indemnidad sexual (artículo 178 y 179 cP); delitos de lesiones por transmisión de enfermedades (artículo 149 cP); agravamiento de penas por lesiones (artículos 147 y ss. CP); daños físicos o psíquicos en el ámbito familiar (artículo 153 cP); o, por supuesto, toda la legislación sobre violencia de género.

${ }^{5}$ La relación de algunos hechos que dan lugar a pretensiones indemnizatorias podrian encuadrarse perfectamente en la definición que de estos derechos ha acuñado el Tribunal Constitucional, como "derecho a no ser escarnecido o humillado ante los demás", palabras de las Sentencias del mencionado Tribunal 85/1992 y 204/2001; o de conductas que puedan desembocar en un "desmerecimiento en la consideración ajena", en terminología de la STc 52/2002.
} 
ni siquiera por el otro miembro de la pareja, considerando que asiste por igual a hombres o mujeres. Si se tratara de un deber, sería incoercible; su inobservancia no acarrearía especiales consecuencias jurídicas directas y su mero incumplimiento no podría presentarse como un cauce indemnizatorio sin más. ${ }^{6}$

No obstante, aunque la sociedad haya cambiado, hay dos circunstancias que conservan importante en la observación de sus consecuencias. La primera, desde luego, es decisiva por lo que veremos en las resoluciones de los tribunales y es lo que más preocupa: que la mujer "dolosa o culposamente" permita que parezcan hijos de su cónyuge - por aplicación de la presunción de filiación matrimonial- los hijos concebidos de otro; pero no por ser infiel -que parece irrelevante-, sino por el engaño ante algo tan importante como es la paternidad. Pero si existe engaño u ocultación de la verdadera paternidad se abre la vía indemnizatoria, que de por sí queda cerrada a la mera constatación de la infidelidad.

La segunda, apuntada ya, es que entramos en el terreno de otros derechos fundamentales, como el honor o la intimidad. Durante décadas, la posible presencia de relaciones adulterinas -especialmente si era la mujer su protagonista- permanecían en el terreno de lo privado. Esto con el fin de preservar la paz familiar, evitar el escándalo o evitar el ridículo en que socialmente quedaba el marido.

En la actualidad, este argumento sigue veladamente presente, aunque es tratado de forma incidental en las sentencias, aludiéndose a "la afectación que puede tener para uno en su imagen y consideración social no ser el padre de quien pública y legalmente en principio lo era".

Fuera de las posibles reclamaciones de daños, la infidelidad tan solo presenta consecuencias directas en ser una causa de desheredación. Aquí sí es igual para hombres y mujeres, por el incumplimiento de deberes conyugales y, poco más, habiendo perdido su consecuencia primordial que era ser causa de separación.

\footnotetext{
${ }^{6}$ No obstante, algún autor mantiene que siempre que no sea recíproca la infidelidad puede dar lugar a un daño resarcible, De VeRDA y BeAmONTE, JOSÉ RAMÓn, "Responsabilidad civil y divorcio en el Derecho español: resarcimiento del daño moral derivado del incumplimiento de los deberes conyugales", Diario La Ley, núm. 6676, p. 21. Así, se entiende también legitimado pasivamente a quien mantiene relaciones extramatrimoniales con el cónyuge infiel.

${ }^{7}$ Palabras de la reciente Sentencia de la Audiencia Provincial de Badajoz, S. 3.a de 5 de septiembre de 2017.
} 


\section{Tratamiento por parte de los tribunales respecto a las reclamaciones de daños por incumplimiento de la fidelidad}

En el marco teórico de la fidelidad se viene avanzando hacia la consideración de la lealtad o exclusividad de los afectos o relaciones anímicas íntimas ${ }^{8}$ en un concepto que se extiende a otros comportamientos. No obstante, en el plano judicial, hoy por hoy, las demandas se plantean tan solo en supuestos de adulterio, en los que además se constata habitualmente que el marido no es el padre de los hijos. Esta circunstancia se descubre, constante matrimonio, y habitualmente se acompaña de la ocultación de la esposa respecto a la verdadera paternidad.

El Tribunal Supremo no se ha ocupado en muchas ocasiones de esta cuestión, por lo cual se ha producido además la coyuntura de que las demandas más importantes se plantean antes de que la infidelidad deje de ser causa de separación. Ello le permite a la sala acudir al criterio de la autosuficiencia de las reglas de derecho de familia para eludir el tratamiento de la cuestión. ${ }^{9}$

Los dos procedimientos principales, muy seguidos en el tiempo y con el mismo ponente, son de 22 de julio de 1999 y 30 de julio del mismo año. Me detendré en ellos para marcar las pautas de las posteriores reclamaciones.

La primera sentencia, la de 22 de julio de 1999, versa sobre una reclamación de 15 millones de pesetas por los alimentos prestados, desde el procedimiento de separación hasta la mayoría de edad, a quien resulta no ser hijo, así como 25 millones por daño moral. Creo que es importante destacar una serie de momentos: se casan en 1956; el hijo nace en 1966; se separan en 1968, concediéndose en 1974 la separación eclesiástica por adulterio y sevicias del marido (que no de la mujer). Cabe aclarar que en esa época eran los tribunales eclesiásticos los que conocían sobre la separación de los casados canónicamente. Volviendo al caso, en 1977, se declara fuera de España la nulidad matrimonial, ratificada en 1978. En 1990, ya bajo la nueva regulación del Código que admite las acciones de filiación, se hacen las pruebas de paternidad y es el padre biológico el que

\footnotetext{
${ }^{8}$ Por todos Echevarría de Rada, Maria Teresa, "Responsabilidad civil por infidelidad conyugal", La Ley Derecho de Familia, núm. 8, p. 2.

${ }^{9}$ En un ámbito diferente, al tratarse de relaciones paterno filiales, pero dentro del derecho de familia, se reconoce el daño moral ocasionado por el comportamiento de la madre que no deja al padre ver a su hija, si prospera la demanda indemnizatoria en el asunto resuelto por la Sentencia del Tribunal Supremo de 30 de junio de 2009. Entablada la demanda cuando la hija ya es mayor contra la madre y contra la Iglesia de la cienciología, se condena a la primera y se absuelve a la segunda, debiendo indemnizar por 60000 euros en concepto de daño moral "ocasionado por quien impide el ejercicio de la guarda y custodia atribuida al otro en una decisión judicial e impide las relaciones con el otro progenitor".
} 
impugna la paternidad, dictándose sentencia el 23 de julio de 1992, mismo año en que se presenta la demanda de daños.

El Tribunal Supremo, en consonancia con los previos pronunciamientos de instancia, considera que no es posible la aplicación del artículo 1902 cc, pues no se aprecia conducta dolosa en el comportamiento atribuido a la demandada, debido a que no parece conocer que el hijo no era de su marido hasta que tiene lugar el procedimiento de impugnación. La sentencia, poco meditada para lo que serían sus posteriores consecuencias, no se acogió favorablemente por la doctrina, pues al no hacer mayores precisiones no debería haber exigido dolo, sino culpa, que es lo que determina el artículo 1902 cc, o bien debería haber hecho alguna referencia al por qué de una mayor exigencia como criterio de imputación.

Es cierto que existen opiniones a favor de un mayor rigor en el criterio subjetivo de imputación de daños en estos casos, reflejo de lo dispuesto en otros ordenamientos, requiriéndose dolo, o al menos culpa grave y no mera negligencia, pero no entra en Tribunal Supremo bajo tal valoración. Ahora bien, sus aseveraciones van abriendo caminos o argumentos al considerar que otra cosa sería la presencia de un comportamiento doloso de la mujer y, al ir determinando indirectamente que el plazo corto de prescripción deberá comenzar a contar desde la firmeza de la sentencia de impugnación de la paternidad.

La siguiente sentencia se dicta el 30 de julio de 1999 (RJ 1999/5726). En este caso, se demanda una serie de pretensiones: daño patrimonial por el mantenimiento de dos hijos hasta el momento de la separación (2 150000 pesetas); devolución de las cantidades abonadas como pensión (50 000 pesetas); daño moral (10 000 pesetas por cada hijo); y nulidad del convenio regulador y que se proceda a una nueva disolución de gananciales.

Nuevamente, la causa viene precedida de un complejo y largo iter procesal. Se casan en 1974, los dos hijos nacen en 1977 y 1981. En 1983 se separan de mutuo acuerdo suscribiendo un convenio regulador. En 1984, ella es quien impugna la paternidad y recae sentencia en 1986, estimando la falta de paternidad biológica del marido. En 1986, ella insta el divorcio, que tiene lugar en 1988, no estableciéndose pensión compensatoria. Se invoca, en este caso, la infracción de lo dispuesto en los artículos 67 y 68, en relación con el artículo 1101.

El Juzgado de Primera Instancia admite tan solo la pretensión por daño moral que reduce a 10000 millones de pesetas. La Audiencia, por el contrario, revoca la sentencia del Juzgado. El Tribunal Supremo, que rechaza el recurso de casación, considera lo siguiente en el fundamento tercero que transcribo textualmente: 
Indudablemente, el quebrantamiento de los deberes conyugales, especificados en los artículos 67 y 68 del Código Civil, son merecedores de un innegable reproche ético-social, reproche que, tal vez, se acentúe más en aquellos supuestos que afecten al deber de mutua fidelidad, en los que, asimismo, es indudable que la única consecuencia jurídica que contempla nuestra legislación sustantiva es la de estimar su ruptura como una de las causas de separación matrimonial en su artículo 82 pero sin asignarle, en contra del infractor, efectos económicos, los que, de ningún modo es posible comprenderlos dentro del caso de pensión compensatoria que regula el artículo 97 e), igualmente, no cabe comprender su exigibilidad dentro del precepto genérico del art. 1101, por más que se estimen contractuales tales deberes en razón a la propia naturaleza del matrimonio, pues lo contrario llevaría a estimar que cualquier causa de alteración de la convivencia matrimonial obligaría a indemnizar.

Concluye, en el fundamento siguiente, que el daño moral generado por la infidelidad no es susceptible de reparación. ${ }^{10}$

No puede considerarse que ambas sentencias sienten una línea jurisprudencial, pues los argumentos jurídicos alegados en las demandas y resueltos por el Tribunal son diferentes. Sin embargo, lo anterior va fijando algunas consideraciones importantes: determinar la naturaleza del matrimonio como un contrato -algo peculiar, pues el incumplimiento de sus obligaciones no da lugar a indemnización alguna-; afirmar que la falta de respeto a los deberes de los artículos 67 y 68 merece un innegable reproche ético social; destacar que el daño moral ocasionado por la infidelidad no es susceptible de reparación económica alguna. Además, se considera que la infidelidad no es una circunstancia por valorar en cuanto al importe de la pensión compensatoria; la "única" consecuencia jurídica contemplada por la legislación es ser causa de separación. También, parece acentuarse el reproche cuando la infidelidad es mutua -encuentro que esto último constituye solo la opinión del ponente, sin que se altere por ello el razonamiento jurídico-. Por último, permitir la indemnización significaría que cualquier alteración de la convivencia matrimonial obligaría a indemnizar.

\footnotetext{
${ }^{10}$ La sentencia es duramente criticada por Ragel Sánchez. La califica como ejemplo de "escasísima sensibilidad de los tribunales hacia lo masculino". Considera abiertamente que el matrimonio es un contrato y que en consecuencia la infidelidad implica un incumplimiento del art. 1101, asi como del 1258 cc. Entiende, por otra parte, que la infidelidad (salvo supuestos como avanzado estado de embriaguez o drogas) es siempre dolosa. Personalmente, no estoy de acuerdo con esta consideración, pues el dolo al que se refiere la sentencia lo es en el aspecto de ocultación de la verdad, y no de la infidelidad en sí.
} 
El pronunciamiento se muestra radicalmente favorable a la inmunidad de las relaciones familiares por falta de cumplimiento de la fidelidad, al tiempo que se acomoda, igualmente, en la postura de considerar que existen unas soluciones propias en el ámbito del derecho de familia. Así, se rechaza igualmente la admisibilidad teórica de cualquier tipo de demandas.

Teniendo en cuenta las diferentes resoluciones de las audiencias recaídas con posterioridad sobre la materia, existía enorme expectación sobre la posibilidad de que el Supremo se manifestara nuevamente sobre la cuestión, una vez desaparecidas las causas de separación. No obstante, en los siguientes pronunciamientos que han llegado al Tribunal sobre la materia, se estima la excepción de prescripción de la acción (corto plazo de un año para las demandas entabladas por la vía del artículo 1902 del cc). Por ello, al día de hoy, no es posible contar con esa esperada opinión.

La STS de 14 de julio de 201011 aprecia la prescripción, tal como hacen las dos instancias anteriores, en una pretensión en la que se demanda por los siguientes conceptos: daño moral por pérdida de una hija, 300000 euros; daño moral por daños físicos y secuelas psicológicas, 100000 euros; daño moral por deterioro de fama, honor, etcétera, 100000 euros; daño moral y enriquecimiento injusto, 14638 euros. Todas las pretensiones fueron ejercitadas al amparo del artículo 1902 cc.

El único aspecto que entra a valorar el Supremo es la presencia de prescripción de la acción, fijando dos criterios importantes: el primero es que nos encontramos en estos supuestos ante un caso de daño duradero o permanente y no continuado. El segundo es que el plazo comienza a contarse en el momento en que se tiene conocimiento de la infidelidad por la notificación de la sentencia recaída en el proceso de filiación que declara no ser hija suya una de los dos habidos en el matrimonio.

A pesar de describirse los sufrimientos del actor, que se van agravando con la sucesión de acontecimientos familiares, niega el Supremo la presencia de un daño continuado, pues ello llevaría a la imprescriptibilidad de la acción. El demandante refiere todo tipo de padecimientos y daños físicos y psicológicos de los cuales responsabiliza a la separación de los cónyuges. Esto incluye una operación de vasectomía que voluntariamente se realiza mientras están casados, así como el agravamiento de la discapacidad de su otro hijo. Se fija como plazo del cómputo de la acción un informe del año 2005, en el cual se dice que empeora su estado; la sentencia de impugnación es del 2003.

\footnotetext{
${ }^{11}$ Comentada por Álvarez Olalla, Pilar, "Prescripción de la acción ejercitada por el marido contra su ex mujer por daños sufridos al determinarse judicialmente la filiación extramatrimonial de una hija, previamente inscrita como matrimonial", Revista Doctrinal Aranzadi Civil-Mercantil, núm. 9.
} 
Dice el Tribunal en el quinto fundamento que:

Ni la separación conyugal es en sí misma ilícita, como tampoco lo es que el cónyuge separado conviva con otra persona, ni desde luego cabe encuadrar en el concepto de daño continuado, a los efectos jurídicos de que no comience el plazo de prescripción de la acción, el recuerdo más o menos periódico, más o menos intenso u obsesivo, de lo sucedido anteriormente, incluso aunque este recuerdo pueda repercutir en el estado de salud del sujeto, ya que de admitir semejante identificación el inicio del plazo de prescripción se prolongaría indefectiblemente, en todos los casos imaginables, hasta la muerte del propio sujeto, y por ende incluyendo la propia muerte entre los daños imputables al demandado por su conducta en cualquier tiempo pasado.

Finalmente, en la Sentencia de 18 de junio de 2012, nuevamente el Supremo aprecia la excepción de prescripción, como había hecho la Audiencia en contra del criterio del Juzgado, que había condenado al pago de 199.038 euros, en aplicación del artículo 1902 cc. Esto por daños físicos y morales, consecuentes de la pérdida de dos hijas concebidas por los demandados que ocultaron su paternidad. No obstante, contra el criterio fijado por la sentencia anterior, seguido por numerosas resoluciones de audiencias, entiende el Tribunal que el plazo no se cuenta desde la fecha de la sentencia que declara no son sus hijas, pues se estaría en plazo, sino desde que se produce el daño. Este consiste en descubrir el engaño en los siguientes términos:

Pretende fijar como dies a quo para la reclamación del daño moral la fecha de la sentencia que resuelve la impugnación de paternidad, por considerar que a partir de ese momento se produjo la pérdida de las hijas, no responde a la realidad conforme a los hechos probados. En el momento en que se dicta la sentencia su estado emocional no sufrió ninguna alteración o quebranto que fuera reseñado en el informe psicológico. El daño moral que se reclama no trae causa de la pérdida legal de las hijas conocida mediante la sentencia de 18 de julio de 2007, que resolvió el procedimiento de paternidad, sino del engaño sobre la forma de concebir a sus dos hijas y el hecho de que tras el divorcio, por decisión de la madre, se fueran a vivir con el padre biológico, situación que le sumió "en una depresión", de la que fue atendido por el psicólogo clínico D. Isidoro, a partir del cual se concretó el daño moral padecido y reclamado. 
En el proceso se trae a colación una serie de informes clínicos y partes de altas y bajas que complican la apreciación de un plazo seguro y objetivo para el cómputo de la acción.

Solo puedo manifestarme radicalmente disconforme con el criterio del Supremo, pues si existe una fecha objetiva es la de la fecha de la firmeza de la sentencia de impugnación de la paternidad, con independencia de que el descubrimiento del engaño sea anterior, pues es evidente que prácticamente en todos los casos habría prescrito la acción. Sin duda existen diversos momentos por valorar: cuando sospecha de su falta de paternidad, cuando le informa el otro cónyuge, cuando se confirma por las pruebas biológicas, cuando termina el proceso de impugnación por sentencia, cuando verdaderamente se separa el progenitor del o los hijos a consecuencia de la separación o divorcio, cuando supera la posible depresión, etcétera. Así, es excesivamente complejo atender a unos $\mathrm{u}$ otros, no a conveniencia de las partes -que para eso están los Tribunales, para fijar un diez a quo seguro-, sino para el propio Supremo, evitando así pronunciarse sobre la materia.

Creo que el impacto del daño moral llegaría cuando el esposo fuera consciente de su falta de paternidad, bien porque alguien se lo comunique, lo descubra por sí mismo, se obtengan los resultados de las pruebas u otras circunstancias. Pero parece más complejo buscar ese momento exacto que determinar el momento en que recae sentencia firme. Si es ese el criterio que había determinado la sentencia anterior, al menos en esta se debería haber secundado el mismo criterio. Parece más bien que la idea del Tribunal está en acogerse al cómputo que permita acortar el plazo de prescripción, evitando entrar en el fondo del asunto.

Lo que sucede, además, es que en todas estas demandas se mezcla una serie de conceptos resarcitorios que, en rigor, tendría cada uno su plazo. Si lo que indemnizamos es el dolor por la pérdida del hijo que se creía propio, sin duda, debería atenderse a la firmeza de la sentencia. ¿Pero también habría acción, aunque no hubiera ocultamiento de la paternidad? Pero, si la acción que da lugar al daño es el comportamiento censurable del que engaña sobre la verdadera paternidad, debería computarse cuando se desvela la verdad, siempre antes del posible ejercicio de acciones de filiación. Y aquí entramos de lleno en un campo menos objetivo: cuando lo sospecha, lo confirma, el sujeto se hace privadamente pruebas de paternidad, se separan y más.

Teniendo en cuenta el número de procedimientos entablados en las instancias inferiores sobre el particular, donde se va elaborando un criterio de resolución, habrá que esperar a que alguno de estos procesos llegue al Supremo. Así, el Tribunal podrá pronunciarse sobre la materia a la vista de los cambios existentes, sin que pueda seguir eludiendo el tratamiento de estas reclamaciones de daños. 
Es imprescindible un detallado análisis de la SAP de Valencia de 2004, sin duda, es la más importante que se ha dictado sobre la materia y la que ha abierto el camino de los pronunciamientos posteriores, como un leading case. ${ }^{12}$ Es posible que lo especialmente determinante de este caso sea la manera en que se desarrollan los hechos, lo que guía el riguroso proceder del Tribunal. Por ello, me extenderé, quizá más de lo debido, en su exposición.

De los cuatro hijos del matrimonio, tres no son del marido. El amante de la esposa, que lo es durante años, está presente en las relaciones familiares, frecuenta la casa, come y cena allí, acude a bañar a los niños, va al hospital cuando ella da a luz. Las madres de los dos saben que es el padre de los tres niños, el amante se lo comenta, entre otros, al vigilante de seguridad de su urbanización. El marido, persona muy conocida y con un importante patrimonio, no sabe nada hasta que se lo cuenta una hija suya, producto de un matrimonio anterior.

El matrimonio se establece en 1987, tienen una hija en 1988. En 1994 pactan separación de bienes, comenzando ella su relación con su amante, que era amigo de su hermano. Nacen los tres niños en 1996, 1997 y 1999. En el año 2001, la hija mayor del marido le informa de la infidelidad. En ese año firman un convenio regulador de separación y se divorcian en 2002. En octubre del mismo año le comunican los resultados de las pruebas, admitiendo ella en un documento la no paternidad de quien era su esposo y la paternidad del amante. Igualmente, ella reconoce una deuda de 96.161 euros por los alimentos indebidamente satisfechos. En noviembre de 2002 se realizan las pruebas para demostrar la paternidad del amante y se dicta sentencia de impugnación en mayo de 2003.

La demanda por daños físicos, psíquicos y patrimoniales se articula con base en el comportamiento culposo o con culpa grave. Se dirige hacia los dos por un total de 12997580 euros y se reclama por los siguientes conceptos: daño moral, 900000 euros por la pérdida de tres hijos, estimándose superior a la pérdida por muerte violenta; daño moral por secuelas y daños físicos, 100 000; deterioro de su fama, honorabilidad y prestigio, 200 000; daño patrimonial por las pruebas de paternidad, 1580.

Frente a la alegación de prescripción, que se desestima, así como las manifestaciones de ella respecto a que no recibía cariño de su marido, quien también la engañaba, el Juzgado concede una indemnización de 50000 euros por daño moral. La sentencia de la Audiencia, que concedería 100000

\footnotetext{
${ }^{12}$ Son muchísimos los pareces doctrinales sobre este pronunciamiento. Véase el comentario de Farnós Amorós, Esther, "El precio de ocultar la paternidad. Comentario a la SAP Valencia, sentencia 7, 2.11.2004", Indret, mayo, 2005.
} 
euros (cantidad sensiblemente inferior a la demandada), basa sus extensas consideraciones en una serie de argumentos que expondré de forma muy resumida. Cita la sentencia del Supremo de 1999, en el sentido de que la única consecuencia de la infracción de la fidelidad es la separación; observa negligencia en la procreación de los hijos extramatrimoniales; considera dolosa la ocultación de la paternidad. La Audiencia utiliza, de contrario, el argumento de la sentencia del Tribunal Superior de 1999 de negar la indemnización por falta de dolo, habiéndose demostrado que los demandados, desde el principio, sabían que los hijos no eran del marido, y aduce que "en ese actuar constante radica el dolo".

La sentencia se extiende en la motivación sobre el daño moral, considerándolo acreditado por las manifestaciones del psicólogo y psiquiatra; estas demuestran los padecimientos del demandante que llega incluso a plantearse el suicidio. Así, aumenta la suma a 100000 euros con base en la siguiente argumentación: "determinamos esta suma porque, como afirma la sentencia, los padecimientos del demandante no pueden imputarse solo al descubrimiento de su no paternidad sino, en gran medida, al conocimiento de la infidelidad de su esposa, siendo el acontecimiento que ahora analizamos el que determina el agravamiento de sus dolencias anteriores”.

Creo que aquí se contradice la sentencia, pues está valorando la infidelidad en sí, con el fin de subir la cuantía de la indemnización, cuando previamente ha rechazado que tenga consecuencias jurídicas. Me cuesta comprender el rechazo, en tan solo un párrafo, a la alegación sobre la infracción de los derechos fundamentales del marido:

Por lo que a los daños morales derivados del deterioro de su fama, honor intimidad y prestigio profesional, estimamos, que si bien puede ser cierto que su no-paternidad fuera un hecho conocido y comentado en los círculos sociales y profesionales en los que se desenvolvía el demandante, no podemos considerar que tales hechos hayan afectado, en la realidad, a su honor, fama o reputación personal o profesional, pues no son susceptibles de dañar el buen nombre, o la consideración que las demás personas puedan tener de él, sin perjuicio de que su estado psicológico le haya impedido llevar una vida personal y social similar a la que desarrollaba con anterioridad.

Comparto las consideraciones sobre la falta de repercusión de los hechos en el prestigio profesional, pero no opino lo mismo sobre el aspecto personal. El hecho de que el demandante sea el último en enterarse de una situación 
como esta creo que permitiría analizar más a fondo esta argumentación. La insultante conducta de la mujer y del amante -tan solo justificable por el hecho de seguir disfrutando de la posición económica de su marido-, con una relación extra matrimonial pública y notoria en la propia casa del matrimonio, puede considerarse atentatoria al honor, nombre y dignidad del demandante.

Es más, de la relación de hechos que se van narrando en la sentencia, se constata un desapego por parte del marido de la relación familiar, pues destina los fines de semana a sus aficiones artísticas y otorga poca dedicación a la mujer e hijos. El dolor, la depresión, las secuelas psiquiátricas y psicológicas parecen más consecuencia del conocimiento de la infidelidad, como bien dice la sentencia, y no de la paternidad. Ello permitiría haber discurrido por este concepto indemnizatorio de la agresión a derechos fundamentales. Personalmente, entiendo que, en supuestos como este, donde parece jactarse públicamente la esposa de que los hijos no matrimoniales se sentarán en el consejo de administración de la empresa, se evidencia una conducta lesiva al honor y dignidad del demandado. Este lo que parece sufrir es el daño moral ocasionado por el hecho de que toda esta situación, cercana al escarnio, sea pública y esté en boca de todos, avanzándose poco y despacio por este camino.

La indemnización es alta para lo que estamos acostumbrados, pero muy inferior a lo solicitado; tampoco hay condena en costas. La difusión de la sentencia en los medios de comunicación, con una identificación de la persona del demandante como dueño de una importante empresa, extendió aún más el conocimiento de los hechos, planteándonos si no estamos ante uno de esos procesos en los que "todos pierden". Ello especialmente en el caso de los hijos nacidos como resultado de la infidelidad, respecto de los que nadie parece preocuparse en este tipo de asuntos judiciales.

A partir de aquí se van definiendo algunas líneas de tratamiento en las distintas Audiencias que paso a exponer resumidamente. Son varios los pronunciamientos que siguen la misma doctrina, entre los que destacaré los que presentan aspectos más peculiares.

SAP de Valencia (sentencia séptima) de 5 de septiembre de 2007 confirma la falta de indemnización por el mero incumplimiento de la infidelidad, exigiendo la procreación con ocultamiento al cónyuge, si bien rebaja la indemnización concedida de 100000 a 12000 euros, atendiendo al escaso tiempo de convivencia y a la convicción, casi desde el nacimiento, de que el hijo no era suyo. SAP de León (sentencia primera) de 30 de enero de 2009, en la que se aprecia dolo en la esposa. Queda acreditado, de su propio testimonio en el previo 
proceso de impugnación de filiación, que buscó la relación extramatrimonial con el fin de tener hijos. Se condena al pago de 30000 euros por daño moral debido al "estado de frustración y sufrimiento" del esposo, aunque no existe una demostración de un proceso depresivo.

SAP de Valencia (sentencia décimoprimera) de 13 de noviembre de 2014. El supuesto de hecho no deja sino de ser sorprendente. El marido conoce su propia esterilidad, aun así ella queda embarazada, pero parece que le dice al marido que ha sido por inseminación artificial (otras veces se habla de fecundación in vitro). Sin embargo, nada ha consentido el esposo sobre la utilización de las técnicas (requisito que exige la ley para determinar al hijo nacido como matrimonial), ni existe una prueba en el proceso sobre tal circunstancia fuera de la manifestación de ella y de testigos. Después descubre el marido que ha sido por gestación normal; de otro modo necesariamente tendría que haber prescrito la acción. Entiende el tribunal que no ha prescrito la acción, pues sigue el criterio de fijar el dies a quo en la fecha de la sentencia de impugnación. Considera que existe dolo en que ella le haya hecho creer que era por inseminación artificial. No obstante, entiende que el hecho de que el marido conociera su propia esterilidad debe afectar a la cuantificación del daño. No alcanzo a comprender este punto, pues, de seguir la argumentación del Tribunal, el daño moral debe ser el mismo, al basarse en la pérdida de la relación paterno filial que determina "una afección psicológica como trastorno adaptativo con ánimo deprimido”. La Audiencia baja de 100000 a 30000 euros la indemnización.

SAP de Jaén (sentencia primera) de 9 de marzo de 2015 (JUR 2015/129380). Nuevamente se trata de un supuesto de hecho complejo, pues ella, que se niega a declarar al respecto, parece que le comunica al marido estéril que se ha quedado embarazada por inseminación artificial, necesitando ayuda de su propia familia para poder decírselo. La pretensión se articula por reclamación de alimentos, ex artículo 1895, y por daño moral, por la vía del artículo 1902. El juzgado absuelve ambas peticiones. La Audiencia rechaza la primera y estima la segunda, condenando al pago de 15000 euros (frente a los más de cuarenta mil reclamados). La Audiencia estima el daño por la ocultación de la paternidad, con conocimiento de la esterilidad del marido, sin revelar la verdad hasta después de la ruptura. En este caso no existe depresión, sino agravamiento de la enfermedad de Crohn que sufre el marido, lo que estima la sentencia para bajar la indemnización solicitada, junto con el poco tiempo de convivencia transcurrido.

SAP de Badajoz (sentencia tercera) de 5 de septiembre de 2017. Considera ocultación deliberada de la verdadera filiación de la niña, haciendo referencia 
a la imagen y consideración social del verdadero padre; se condena al pago de 25000 euros.

SAP de Girona (sentencia segunda) de 19 de abril de 2018. En este caso, la petición indemnizatoria se articula en el marco de un procedimiento de filiación. Se reconoce el daño moral (40 000 euros), por la deliberada ocultación de la verdadera paternidad, así como el daño patrimonial consistente en los alimentos abonados desde la separación y los posteriores por formación universitaria (107 269). Aunque no se admite la petición de los satisfechos antes de la separación de los esposos, en el entramado de la relación matrimonial y satisfacción de las cargas del matrimonio se admite claramente la demanda por la vía de la responsabilidad civil (ex artículo 1902 cc). De tal modo, se determina que se hubiera rechazado, al hacerlo por enriquecimiento injusto o pago de lo indebido.

Encontramos otro grupo de resoluciones que avanzan hacia un menor rigor a la hora de juzgar la presencia de responsabilidad, llegando a presuponer culpa en diversos comportamientos.

SAP Barcelona (sentencia décima octava) de 16 de enero de 2007. Ya no se baraja el concepto de dolo, sino que se considera que la relación simultánea con dos hombres debió hacer sospechar a la mujer de que el hijo podía no ser de su marido. Por otra parte, tal valoración es lógica, pues en los 17 primeros años de matrimonio no se había quedado embarazada. La negligencia consiste en no hacerse las pruebas correspondientes, especialmente por la generalización y facilidad de su uso, lo cual resultó en una condena de indemnización por 15000 euros.

SAP de Cádiz (sentencia segunda) de 3 de abril de 2008. La detallada sentencia alude al "incumplimiento cualificado" del deber de fidelidad. Basta ya el mantenimiento de relaciones con dos personas al tiempo, debiendo desde el principio hacer lo necesario para determinar la paternidad. Esto para cumplir un deber de información y desdeñar el criterio de una culpabilidad reforzada. La sentencia contiene un extenso alegato a favor de que el incumplimiento de los deberes sea objeto de indemnización por la vía del artículo 1902, con el fin de dotar de contenido al matrimonio como institución protegida por la Constitución. En tal sentido, se considera que quien contrae matrimonio adquiere la legítima expectativa de que su cónyuge cumpla sus compromisos matrimoniales. Por ello, debe tener derecho a una indemnización si el "incumplimiento cualificado" le ha causado daños. Así, la sentencia concede finalmente una indemnización de 30000 euros.

SAP de Barcelona (sentencia décima séptima) de 27 de octubre de 2011. Se demandan más de 200000 euros por diversos conceptos, que van rebajándose 
en las sucesivas instancias hasta quedar en 20 000. La sentencia es una de las que van atenuando los requisitos, pues nada se plantea sobre dolo o mala fe. Ello debido a que el hecho generador es la ocultación de la paternidad durante quince años. Este es uno de los pronunciamientos en los que claramente se determina que el plazo de prescripción comienza con la fecha de la sentencia de impugnación de la paternidad.

SAP de Cantabria (sentencia segunda) de 3 de marzo de 2016. Con un extenso recorrido expositivo sobre los pronunciamientos anteriores, esta sentencia nuevamente basa la apreciación de responsabilidad en la ocultación de la paternidad. Si bien la esposa manifiesta haberlo comunicado, el Tribunal entiende que la demandada debe dudar de la paternidad cuando se mantienen relaciones extramatrimoniales, siendo apropiado resolver la duda. La condena alta, de 30000 euros, basa su consideración en que el "trastorno se produjo por causa de la ruptura traumática con su esposa, pero se agravó claramente con el conocimiento de la exclusión de su paternidad". La resolución insiste en fijar el plazo de la acción a partir del momento de la firmeza de la sentencia impugnatoria.

Existe también un buen número de pronunciamientos que rechazan la reclamación por incumplimiento de la fidelidad, como por ejemplo sAP de Barcelona (sentencia decimocuarta) de 31 de octubre de 2008. En esta, se observa falta de dolo, al manifestar que:

La sala comprende la desazón del actor y no niega el juicio de reproche que merece el incumplimiento del deber de fidelidad y la negligencia de los demandados en siquiera dudar de la posibilidad de una paternidad alternativa, en los tiempos de la concepción. Pero, en trance de resolver la acción indemnizatoria, debe concluir que no está prevista en nuestro ordenamiento la responsabilidad por pérdida de la relación paterno filial, derivada de una infidelidad, para los casos de culpa o negligencia.

También la SAP de Castellón (sentencia tercera) de 10 de febrero de 2009; la SAP de La Coruña (sentencia tercera) de 8 de noviembre de 2010; la SAP de León (sentencia segunda) de 10 de noviembre de 2010, que presenta la particularidad de ser la esposa quien demanda al marido infiel, o la reciente sAP de Alicante (sentencia novena) de 6 de noviembre de 2017, en la que se desestima la pretensión entablada contra el tercero, donde no se aprecia dolo ni culpa en no hacerse las pruebas de paternidad. 


\section{Breves conclusiones}

De lo expuesto hasta ahora, podemos afirmar que las sentencias del Supremo no arrojan mucha solución sobre la materia, y el camino que ha seguido la jurisprudencia menor parte en gran medida de la mencionada sentencia de Valencia dictada en el 2004. Sus consideraciones y lo resuelto por los pronunciamientos que la siguen van avanzando claramente hacia la constatación de un deber de información que, con más o menos presupuestos, le incumbe al cónyuge que mantiene paralelamente una relación extramatrimonial sobre la paternidad del o los hijos que nazcan a partir de ese momento. Sin embargo, es inevitable que en las consideraciones de los jueces se deslicen apreciaciones sobre el impacto del descubrimiento de la infidelidad, el dolor de la ruptura matrimonial, entre otros factores. De tal modo, se transita por la vía de volver a la valoración del deber que precisamente se trata de obviar. Este deber de información, moviéndose en el campo de la filiación, se extiende claramente a quienes conviven sin estar casados.

En otras ocasiones, el criterio de imputación va atenuándose: se deja de exigirse dolo para pasar a entender que es negligente quien no realiza las pruebas de paternidad correspondientes con el fin de averiguar la paternidad. Todo ello propicia que nos alejemos del campo de la fidelidad, pues, en la actualidad, si no cambian las consideraciones de los Tribunales, no prosperará un buen número de supuestos que por definición quedarían fuera. Ejemplo de ello son las relaciones abiertas, donde ambos cónyuges deciden ser libres en el ejercicio de su sexualidad; el reconocimiento de la relación extramatrimonial por parte de la mujer, antes o en el momento de la concepción; el posible perdón del cónyuge, con independencia de que el hijo sea suyo o no; las infidelidades con personas del mismo sexo en las que esté excluida la procreación; la comunicación o información al cónyuge o pareja de que se han realizado pruebas de paternidad y el hijo no es suyo; las infidelidades en las que no exista generación, con independencia de su duración, o ya, en el plano de la conjetura, ¿aquellas en las que el esposo o pareja no sufriera depresiones o agravamiento de enfermedades por entender que no existe daño moral?

Evidentemente, en todos los casos en que se comunique la infidelidad y sus consecuencias, en cuanto a la generación, lo habitual será la ruptura del matrimonio. Con ello, el comportamiento que la visión de los tribunales propicia es, precisamente, el que rompe con la paz familiar; exactamente lo contrario a lo que sucedía antes. Antes, la posible infidelidad se mantenía oculta, especialmente por no airear el adulterio de la esposa con las connotaciones sociales que pudieran desencadenarse. En oposición, lo que aconseja 
ahora la salvaguarda de los intereses económicos del infiel es precisamente comunicarlo de inmediato para quedar a salvo de la reclamación, cumpliendo con ese deber de información.

No obstante, en muchos casos, el tratamiento que dispensan los tribunales a estos supuestos parece cercano a los daños punitivos. Viendo el coste que suponen algunos pleitos, en los cuales se reconocen prolíficas indemnizaciones después de un peregrinaje procesal, plagado de gastos de letrados y procuradores, ¿no estamos buscando subyacentemente una reprensión pública de la mujer infiel?

No creo que estemos ante resultados reparadores - una de las funciones que debe alcanzar el derecho de daños en el marco de las relaciones familiares-, sino meramente punitivos. Buena prueba de ello es el poco interés que se dedica en los procesos de las relaciones con los hijos que se creían propios, cuando aparentemente no se lucha por el establecimiento de derechos de visitas con aquellos que durante años se han tenido como hijos propios. Si de antemano la mayoría de los abogados informarán sobre la dificultad de obtener el reintegro de los alimentos satisfechos, así como de la obtención de una considerable suma, ¿merece la pena pleitear si no es por llevar al infiel ante la justicia?

En suma, lo que están admitiendo los tribunales no es un incumplimiento del deber de fidelidad, pues la cualificación de los requisitos que dan lugar al reconocimiento de daños sale de la esfera de los simples deberes (la infidelidad en sí no es indemnizable). Así, transitan hacia fuera del matrimonio, como es el caso de las parejas no casadas.

La indemnizabilidad de los incumplimientos de deberes, en sí, no debe ser permitida; por una parte, porque las infracciones graves y flagrantes están tipificadas penalmente o alcanzan la protección de los derechos constitucionales. De tal modo, nos quedamos con los incumplimientos de comportamientos que no deben alcanzar resarcimiento, ni dentro ni fuera del matrimonio, pues tales pretensiones se niegan a los extraños.

La ruptura del matrimonio, motivada en muchos casos por la presencia de esas infracciones, es dolorosa. Pero ese sentimiento no puede considerarse un daño moral resarcible, por mucho que cueste asumir determinadas situaciones, así como no lo es romper una amistad por deslealtad del amigo, o que nos suspendan en unas oposiciones, o que quedemos sumidos en una depresión por la jubilación. No apoyar anímicamente al otro o no compartir tareas domésticas, o no serle fiel no es en sí mismo un comportamiento ilícito a la vista de lo resuelto por los operadores jurídicos varios.

Por otra parte, no puede obviarse que la ruptura matrimonial dispone de un trato de favor mediante el reconocimiento de compensaciones que eliminan 
algunos presupuestos del daño material, así como lo hacen igualmente las reglas de disolución y liquidación de régimen económico matrimonial.

Otra cosa son los casos de ocultación de la paternidad, los cuales sí creo que deben acarrear cierto tipo de consecuencias. Quizá pudieran solventarse por la vía de reconocer alguna especie de indemnización en el marco de las acciones de filiación, así como de una regulación adecuada de la materia de la retroactividad de las reclamaciones de alimentos, pero ya es un tema diferente.

\section{Bibliografía}

Álvarez Olalla, Pilar, "Prescripción de la acción ejercitada por el marido contra su ex mujer por daños sufridos al determinarse judicialmente la filiación extramatrimonial de una hija, previamente inscrita como matrimonial”, Revista Doctrinal Aranzadi Civil-Mercantil, núm. 9.

De Verda y Beamonte, José Ramón, "Responsabilidad civil y divorcio en el Derecho español: resarcimiento del daño moral derivado del incumplimiento de los deberes conyugales", Diario La Ley, núm. 6676.

Echevarría de Rada, María Teresa, "Responsabilidad civil por infidelidad conyugal", La Ley Derecho de Familia, núm. 8.

Farnós Amorós, Esther, "El precio de ocultar la paternidad. Comentario a la SAP Valencia, sentencia 7, 2.11.2004", Indret, mayo, 2005.

García Amado, Juan Antonio, "La familia y su derecho", Diálogos Jurídicos, Universidad de Oviedo, Aranzadi, 2016. 